Published in final edited form as:

Lancet. 2011 February 5; 377(9764): 505-515. doi:10.1016/S0140-6736(10)61894-6.

\title{
Health care and equity in India
}

\author{
Yarlini Balarajan ${ }^{1}$, S Selvaraj ${ }^{2}$, and S V Subramanian ${ }^{3}$ \\ ${ }^{1}$ Department of Global Health and Population, Harvard School of Public Health \\ ${ }^{2}$ Public Health Foundation of India \\ ${ }^{3}$ Department of Society, Human Development and Health, Harvard School of Public Health
}

\section{Abstract}

India's health system faces the ongoing challenge of responding to the needs of the most disadvantaged members of Indian society. Despite progress in improving access to health care, inequalities by socioeconomic status, geography and gender continue to persist. This is compounded by high out-of-pocket expenditures, with the rising financial burden of health care falling overwhelming on private households, which account for more than three-quarter of health spending in India. Health expenditures are responsible for more than half of Indian households falling into poverty; the impact of this has been increasing pushing around 39 million Indians into poverty each year. In this paper, we identify key challenges to equity in service delivery, and equity in financing and financial risk protection in India. These include imbalanced resource allocation, limited physical access to quality health services and inadequate human resources for health; high out-of-pocket health expenditures, health spending inflation, and behavioral factors that affect the demand for appropriate health care. Complementing other paper in this Series, we argue for the application of certain principles in the pursuit of equity in health care in India. These are the adoption of equity metrics in monitoring, evaluation and strategic planning, investment in developing a rigorous knowledge-base of health systems research; development of more equityfocused process of deliberative decision-making in health reform, and redefinition of the specific responsibilities and accountabilities of key actors. The implementation of these principles, together with strengthening of public health and primary care services, provide an approach for ensuring more equitable health care for India's population.

\section{INTRODUCTION}

\begin{abstract}
India accounts for a substantial part of the global burden of disease, with $18 \%$ of global deaths and $20 \%$ disability-adjusted life-years (DALYs). ${ }^{1}$ While the growing burden of chronic disease accounts for $53 \%$ of deaths (44\% of DALYs), $36 \%$ of deaths ( $42 \%$ of DALYs) are attributable to communicable diseases, maternal and perinatal conditions, and nutritional deficiencies suggesting a protracted epidemiological transition. ${ }^{2}$ One-fifth of maternal deaths and one-quarter of child deaths in the world occur in India. ${ }^{3,4}$ Life expectancy at birth is 63 years for males and 66 for females, and the under-5 mortality rate of 69 per 1000 births in India falls behind the South-East Asia regional average. ${ }^{5}$
\end{abstract}

\footnotetext{
Address for Correspondence: S V Subramanian, Associate Professor, Department of Society, Human Development and Health, Harvard School of Public Health, 677 Huntington Avenue, Kresge Building, $7^{\text {th }}$ Floor, Boston, MA 02115-6096, U.S.A; Tel: 617 432 6299; Fax 617432 3123, svsubram@hsph.harvard.edu.

Contributions: SVS, YB conceptualized the study, designed the analysis, interpreted the results, wrote and critically revised the manuscript. SS contributed to the analysis and writing. All authors have read and approved the manuscript.

Conflict of Interest: YB, SS, SVS declare no conflict of interest.
}

Financial Disclosure YB, SS, SVS declare no financial disclosure. 
The above statistics, however, mask the marked variation in the distribution of health within India. While health outcomes have improved over time, they continue to be strongly patterned along dimensions such as gender, caste (Side Panel 1), wealth, education, and geography. ${ }^{6-8}$ For example, the infant mortality rate among the poorest and richest wealth quintiles was 82 and 34 per 1000 births in 2005-6, respectively (Figure 1). ${ }^{9}$ Similarly, the under-5 mortality rate among mothers with no education compared to those with secondary or higher education was 106 and 49 per 1000 births, respectively. As shown in Figure 2, typically the state variation in under-five mortality tends to be largely patterned along the level of state economic development. Substantial geographic inequalities in health outcomes in India, with life expectancy ranging between 56 years in Madhya Pradesh to 74 years in Kerala; a difference of 18 years, which is higher than the provincial differences in life expectancy in China, ${ }^{10}$ or the inter-state differences in the United States. ${ }^{11}$

Many of these health inequalities result from a broad set of social, economic, and political conditions which influence the level and distribution of health within a population. Addressing these structural factors which constitute the social determinants of health (Box 1), is important as some of these health inequalities may represent health inequities that result from the unjust distribution of primary social goods, power and resources. ${ }^{12,13}$ Redressing any inequities in health can be considered a primary goal of public policies, with health systems having a specific and special role in achieving equity, alongside efficiency, in the distribution of health in a population and the exposure and vulnerability to illhealth. ${ }^{14-16}$

Equity in health and equity in health care have been a longstanding guiding principles, with commitment to the serving the needs of the poor and underprivileged being central to health policy documents. The 'Health Survey and Development Committee Report'of 1946 led by Sir Joseph Bhore set out a detailed vision and plan for providing universal coverage to the population through a government-led health service. ${ }^{17}$ Since then, health policies and priorities have been outlined in the "Five Year Plans", developed as a part of India's centralized planning and development strategy. The first official National Health Policy, put forward in 1983, reiterated the need for universal comprehensive care. ${ }^{18}$ Influenced by the Alma Ata declaration, the policy emphasized the primary health care approach, in addition to recommending decentralization of the health system, improved community participation, and expansion of the private sector to reduce the burden on the public sector. While the next National Health Policy of 2002 continued to champion India's vision, this was to be carried out on the "basis of realistic considerations of capacity". ${ }^{19}$ More recently, in 2009, the Government of India drafted a National Health Bill proposing the legal framework to recognize the 'right to health and 'right to health care' with a stated recognition to address the underlying social determinants of health. ${ }^{20}$ However, implementing policy commitments to equity in health care remains a challenge given India's institutional and implementation capabilities, ${ }^{21}$ even though this is a challenge facing the global health community, and not unique to India. ${ }^{22}$

In this review, we begin by describing the inequalities in access to health care. Using a supply-demand framework, we discuss the key challenges facing the health system in its pursuit of equity in service delivery and equity in health financing and financial risk. We conclude by arguing for the need to explicitly incorporate and implement an equity perspective in the development of a health care system in India and propose a set of principles are necessary to ensure more equitable health care for India's population. 


\section{INEQUALITIES IN HEALTH CARE}

The inverse care law, whereby those with the greatest need for health care have the greatest difficulty in accessing health services and least likely to have their health needs met, ${ }^{23}$ is highly applicable in India. ${ }^{24-26} \mathrm{We}$ conceptualize access as the ability to receive a specified set of services, at a specified level of quality, subject to a specified constraint of inconvenience and cost, ${ }^{27}$ and use utilization of selected health services as a proxy for access. To illustrate the persisting inequalities and inequities in health care in India, we focus on access to maternal and child health services, as the disease burden relating to communicable, maternal and perinatal conditions are in part addressed by access to these services.

\section{Inequalities in preventative health care}

Utilization of preventive services such as antenatal care and immunizations remains suboptimal, with marked variation in the utilization of these services by gender, socioeconomic status, and geography. In 2005-6, the national immunization coverage was $44 \%$. Inequalities in immunization exist by household wealth and education, with absolute and relative inequalities showing signs of reduction over time (Figure 3). Inequalities exist by caste: in 2005-6, immunization coverage among scheduled tribes and scheduled castes was $31.3 \%$ and $39.7 \%$ respectively compared to $53.8 \%$ among other castes with absolute inequalities between these castes increasing over time. Coverage remains higher in urban areas (58\%) compared to rural areas (39\%), although absolute and relative urban-rural differences have decreased over time. Over time, the absolute gender gap has increased with an absolute $2.6 \%$ gender gap in 1992-3 increasing to 3.8\% gender gap in 2005-6.

Similar patterns in inequalities are seen for antenatal care coverage (eFigure 1). In 2005-6, $77 \%$ of Indian women during their pregnancy received some form of antenatal care in the three years preceding the survey, even though only $52 \%$ had the recommended three or more visits. Overall, progress in antenatal care coverage has increased over time. Inequalities by wealth, education and urban-rural residence however persist, even though absolute and relative inequalities have decreased over time. For both these preventive services, there are considerable state differences, with both the number of antenatal visits and the type of services provided during these visits varying.

\section{Inequalities in curative health care}

Inadequate access to appropriate maternal health services remains an important determinant of maternal mortality. Although the rates of institutional delivery have increased over time, only $40 \%$ of women in India report giving birth in a health facility for their last birth in 2005-6. There exists a six-fold difference between the richest and poorest quintile in institutional delivery (eFigure 2). Although this relative difference in inequality has declined over time, the absolute percentage point difference in the prevalence of institutional delivery between the poorest and richest has increased from 65\% in 1992-3 to 70\% in 2005-6.

Among scheduled tribes, institutional delivery was $17.1 \%$ in $1998-9$ with minimal improvement to $17.9 \%$ in $2005-6$.

Similarly, there are marked variations in general hospitalization rates by gender, wealth, and urban-rural residence. ${ }^{28}$ Some of this variation may be due to differences in actual and perceived need and health seeking behavior; indeed, there is evidence of gender inequalities in untreated morbidity with the likely underreporting of illness among women. ${ }^{24}$

Although the poor are more likely to seek care in the public sector, the rich capture more of their share of public services because they are more likely to utilize these services, and also seek care in higher level facilities. ${ }^{29}$ The rich are also more likely to be hospitalized, and 
have longer in-patient stays in the public sector. ${ }^{30}$ Previous analysis of public sector health services demonstrated that the preventive care services of immunization and antenatal visits show a more equitable distribution than most curative care. ${ }^{29}$

In summary, even though progress has been made, inequalities continue to persist in access to services. There are differential trends in relative and absolute inequalities suggesting differential uptake and access to services by different groups and understanding these nuanced patterns has policy implications for better targeting services to vulnerable groups.

\section{CHALLENGES TO ACHIEVING EQUITY IN HEALTH CARE}

Achieving equity in access to health care requires overcoming several factors that challenge equity in service delivery, and equity in health financing and financial risk protection. We examine these factors through a interrelated supply-demand framework for health services (Figure 4). On the supply-side, we discuss issues related to achieving equity in service delivery which ensure access to the appropriate level of well resourced services, and on the demand-side we examine equity in health financing and financial risk protection and consider how the costs of seeking care may limit utilization, especially when out-of-pocket expenditures are extremely high.

\section{Supply-side factors}

Suboptimal and inequitable resource allocation-The efficient allocation of resources between different levels of services and between different geographical regions is critical in ensuring the physical availability of the appropriate level of adequately resourced health services. ${ }^{15}$ In India, this challenge is compounded by low levels of public financing with marked state variation in financing (see Series paper on financing). India's total expenditure on health was estimated at $4.13 \%$ of the Gross Domestic Product (GDP) in $2008-09$, with public expenditure on health being $1.10 \%$ of the share of GDP. ${ }^{31}$ Private expenditures on health have remained high over the last decade, ${ }^{32}$ with India having one of the highest proportions of household out-of-pocket expenditures on health in the world, estimated at $71.1 \%$ in $2008-09$.

Central government per capita expenditures disbursed to states are relatively similar, irrespective of the different capabilities and health needs of different states. ${ }^{33}$ There is also wide variation in state expenditures on health, with a seven-fold difference between the major states. For example, public expenditures per capita in Bihar is estimated at 93 Rupees compared to 630 Rupees per capita in Himachal Pradesh in 2004-5. ${ }^{31}$ Besides inter-state variations, a greater proportion of resources are directed towards urban-based services, and higher level services, with $29.2 \%$ of public expenditures (both Central and State) allocated to urban allopathic services compared to $11.8 \%$ of public expenditures allocated to rural allopathic services in 2004-5. This imbalanced allocation is compounded by the private sector's bias toward higher level curative services, which determined by market forces, tend to be centered in wealthier urban areas. The private sector dominates service provision of high-end curative services, and evidence from national household surveys demonstrates the expanding role of the private sector over the last two decades emerging as the predominant provider of inpatient care. ${ }^{34}$

Physical access-Physical access is a major barrier to both preventive and curative health services for India's large rural population (>70\%). The number of government hospital beds in urban areas is more than twice the number in rural areas, ${ }^{35}$ and the rapid development of the private sector in urban areas has resulted in an unplanned and unequal geographical distribution of services. ${ }^{36}$ Although urban concentration of facilities may encourage economies of scale, the distribution of services is an important factor affecting 
equity in health care, primarily as many vulnerable groups tend to be clustered in areas where services are scarce. In 2008, there were an estimated 11289 government hospitals with 494510 beds, with marked regional variation ranging from 533 persons per government hospital bed in Arunachal Pradesh to 5494 persons per government hospital bed in Jharkhand..$^{35}$

As physical distance to facilities is a key determinant for access, ${ }^{37,38}$ overcoming this through outreach or better transport, roads and communication networks is important for reaching disadvantaged and physically isolated groups, such as Scheduled Tribes. In addition, distance remains a greater barrier for women. ${ }^{39}$ Furthermore, physical access of services does not necessarily assure utilization since the costs associated with seeking care also preclude uptake, even when services are physically available.

Human resources for health-India faces the challenge of sustaining adequate level, skill mix, quality and distribution of human resources for health, across states and especially in poorer rural areas. (see Series paper on HRH). Rural areas are served by over a million rural practitioners, many of whom are not formally trained or licensed. ${ }^{40}$ Since the most disadvantaged are more likely to receive treatment from less qualified providers, India's human resources for health challenge presents a further hurdle for assuring equity in health care (see Series paper on HRH).

Quality-Quality is a complex construct capturing several different paradigms such as safety, effectiveness, timeliness and patient-centeredness, and can broadly be divided into service and clinical quality. ${ }^{15}$ In India, quality in health care is not well understood, with limited evidence to infer how quality affects equity in health care. ${ }^{41}$ Adequate regulation of the public and private sector has been difficult to achieve. Even though there exists a complex regulatory framework, with an extensive set of legal instruments, such as the Indian Penal Code, the Indian Contract Act and the Law of Torts, effective enforcement and implementation remains problematic. ${ }^{42,43}$

Studies suggest that there is high absenteeism among health workers (reported to be higher than $40 \%$ in some studies), limited opening hours, limited availability of drugs and other supplies, poor physical environments, and poor provider training and knowledge. ${ }^{30,44-47}$ (see Series paper on HRH) In urban centers, low competence among both private and public providers has been documented, with providers visited by the poor being less qualified and knowledgeable. ${ }^{47} \mathrm{~A}$ study in rural Rajasthan reported that most private providers were unqualified, with fewer than $40 \%$ having a medical degree, and almost $20 \%$ not having completed secondary school. ${ }^{44}$ Dissatisfaction with the quality of care in the public sector is proposed as the reason that the poor seek care in the private sector. ${ }^{30}$ Reducing the exposure to clinically unnecessary and potentially harmful treatments and influencing demand for appropriate health seeking are emerging as important issues. ${ }^{47-5045,51}$ As the disadvantaged and poor are more likely to receive poor quality services, ${ }^{36,52}$ this has important implications for assuring equity in health care (see Series paper on HRH).

Regulatory deficiencies in the private sector were partly redressed by the inclusion of private medical practice under the Consumer Protection Act in 1986, with recognition of patient's rights and resolutions through "Consumer Forums". ${ }^{53}$ Other authorities involved with regulating the private sector include the Central Drug Standard Control Organisation (CDSCO), National Pharmaceutical Pricing Authority (NPPA), State Drug Controllers and the Nursing Home Acts of different cities and states, and until recently the Medical Council of India. ${ }^{54}$ (see Series paper on HRH) 


\section{Demand-side factors}

Financial constraints to demand-Low levels of public financing, lack of a comprehensive risk pooling mechanism, and high out-of-pocket expenditures in the context of rising health costs are key factors impacting equity in health financing and financial risk protection.(see Series paper on financing) Evidence from national expenditures surveys suggest that inequalities in health financing have worsened over the last two decades. ${ }^{34}$ Only around 10\% of the Indian population are covered by any form of social or voluntary health insurance, which is mainly offered through government schemes for selected employment groups in the organized sector (e.g., Employee State Insurance Scheme, Central Government Health Scheme). ${ }^{52}$ Private insurance entered the Indian market after passage of the Insurance Regulatory and Development Authority Bill in 1999, and private insurance companies account for $6.1 \%$ of health expenditures on insurance. ${ }^{55,56}$ Community-based health insurance schemes and schemes for the informal sector which encourage risk pooling cover less than $1 \%$ of the population. ${ }^{52,57}$ Thus out-of-pocket expenditures and the associated inequities predominate.

The poor are more price sensitive to health care, ${ }^{58}$ they are less likely than the rich to seek care when they are ill, and this is more so in rural areas. ${ }^{28}$ Moreover, the poor are more likely to report financial cost as a barrier as the reason for foregoing care when suffering from illness, and this has increased over time for both the rural and urban poor. ${ }^{31}$ The cost of maternal care, for instance, is out of the reach of the poorest households (lowest two deciles), where the average costs incurred during the year of childbirth exceeds their annual 'capacity to pay.' 59

Out-of-pocket expenditure on health, as a proportion of household expenditure, has increased over time, in both rural and urban areas. ${ }^{34,55}$ Expenditures on both inpatient and outpatient health care are consistently higher in private facilities as compared to public facilities; and the expense of non-communicable diseases exceeds that of communicable diseases. ${ }^{60}$ Notably, the proportion of expenditures spent on health has increased more for the poorest households (Figure 5). ${ }^{55}$

The financial burden of both inpatient and outpatient care is consistently greater for rural households, compared to urban households; with rapid increase in inpatient expenditures per admission. In 2004-5, around 14\% of rural households and $12 \%$ of urban households spent more than $10 \%$ of their total consumption expenditure on health care. Hospitalization is also expensive; hospitalized Indians spend $48 \%$ of total annual expenditures/savings on health care, with more than one-third of hospitalization expenses drawn borrowing money or selling assets to cover medical care (Figure 5). ${ }^{30,60}$ Even for inpatient care, drug expenditures account for the largest burden of this cost. ${ }^{61}$ Drugs, diagnostic tests and medical appliances account for more than half of out-of-pocket expenditures. ${ }^{60}$

Evidence from several developing countries demonstrate that out-of-pocket expenditures on health exacerbate poverty. ${ }^{62}$ Inadequate financial risk protection to protect from the financial shocks associated with the costs of medical treatment have been shown to push households further into poverty. ${ }^{55}$ IIl-health and health expenditures are the reason for more than half of households which fall into poverty. ${ }^{63}$ In 2004-05, around 39 million (30.6 and 8.4 million in rural and urban areas, respectively) of Indians fall into poverty as a result of out-of-pocket expenditures each year. ${ }^{34,61}$ These estimates it must be noted fail to take into account the impact on people already below the poverty line who are pushed even deeper into poverty or those groups who are forced to forego health care as a result of the financial barriers to access. The impact of out-of-pocket expenditures on poverty has been increasing, both in absolute and relative terms. ${ }^{34}$ The impact of health expenditures are greater in rural 
areas and in poorer states, where a greater proportion of the population live near the poverty line, ${ }^{61}$ with burden falling heavily on scheduled tribes and scheduled castes (Figure 6).

Health spending inflation-Health spending inflation is another major factor constraining access to health services and equity in financing. Between 1986-7 and 2004, the absolute expenditures per outpatient visit and inpatient visit in rural and urban areas increased ${ }^{64}$ impacting the ability of the poorest to access services. Although costs have increased in both the public and private sector, the increase has been much faster (over $100 \%$ ) in the private sector. ${ }^{34}$ Growth in expenditures has been fastest for rural inpatient services. ${ }^{65}$

Expenditures on drugs have been increasing over time, and drug costs constitute a greater proportion of out-of-pocket expenditures for the poor compared to the non-poor. (eFigures 3 and 4) Current shortcomings in the effectiveness and adequacy of drug price control, regulation of the pharmaceutical market, and procurement and distribution mechanisms exacerbate inequitable access to affordable quality drugs. ${ }^{66,67}$ The share of drugs under price control has declined markedly; whereas around $90 \%$ of drugs were under price control in the 1970s, only around $10 \%$ are today. ${ }^{66}$ Furthermore, analysis of changes in drug prices shows that between 1996 and 2006, medicines in a select basket of drugs rose by 40\%; whereas the prices of drug on the essential drug list rose by $15 \%$, drugs not on the essential drug list and not price controlled rose by $137 \% .{ }^{67}$

Importantly, these financial constraints of health care do not include the additional costs associated with seeking care, such as the opportunity costs of forgone wages, transportation, childcare, or the loss of earnings due to ill-health. ${ }^{58,68}$ Corruption in the health sector is not uncommon. ${ }^{69}$ In one study of the government sector in India, $20 \%$ of respondents reported irregular admission processes, and 15\% reported corruption after admission, with doctors (77\%), and other hospital staff (67\%) being the likely perpetrators ${ }^{70}$. This mostly takes the form of bribes extorted directly (55\%) paid in order to receive proper treatment during admission. The implications of these additional costs is likely to disproportionately impact poorer households' capacity to seek care. ${ }^{60}$

Behavioral factors affecting individual demand for health care-Factors which affect access to knowledge, education and information can alter the appropriate demand for and compliance with health services, ${ }^{71}$ by influencing health beliefs, perceptions of health and illness, health seeking behavior and compliance with therapy. ${ }^{72}$ These barriers may be further shaped by sociocultural factors, such as sex, religion and cultural beliefs. Building health 'consciousness' and health literacy among the socially disadvantaged is a necessary step to encourage appropriate demand for available health services ${ }^{73}$ For example, $72 \%$ of women who did not give birth in a health facility, reported that they did not feel that it is necessary. ${ }^{9}$

\section{PRINCIPLES TO ACHIEVING EQUITY IN HEALTH CARE}

The challenges facing the health system in its quest for equity in health care are substantial. These challenges are further complicated by the heterogeneity in the scale and interplay of these barriers which act differentially at state, local and individual level, which demand contextually relevant solutions. In the last few years India has been making considerable progress, with several examples of innovative pilot programs and initiatives operating in the public and private sector,(see Series paper on financing, HRH, and Call to action) with the most noteworthy government-led initiative being the National Rural Health Mission (NRHM) which was established in 2005 (Box 2). This initiative has signaled the repositioning and rejuvenation of the public health system and in doing so has placed the 
health needs of the disadvantaged and health equity firmly on the agenda again..$^{74,75}$ However, it remains to be seen whether the NRHM, and other initiatives will live up to their claims and overcome the challenges to achieving equity in health care. ${ }^{74-76}$

While subsequent papers in this Series address specific aspects of health system performance and recommend policy reforms to ensure equity in health care (see Series paper on financing, $\mathbf{H R H}$ ), the Call to action proposes a specific strategy with goals and targets to achieve universal health care in India by 2020 (see Call to action). To complement and support these papers, here we propose the following guiding principles to help achieve equity in health care.

\section{Equity metrics}

Equity metrics needs to be integrated into all health system policy and implementation strategies, and at every stage of any reform process. Recommended by the Commission on Social Determinants and others, ${ }^{14,77,78}$ this entails applying an equity-focused approach to the collection, use and application of data on health outcomes and processes of health care, and during monitoring and evaluation of health systems performance. This requires an intelligence system built across the health system network, spanning the public and private sector, and allopathic medicine and non-allopathic medicine (Ayurveda, Yoga and Naturopathy, Unani, Siddha, and Homeopathy (AYUSH), aligned with international principles and standards for health metrics. ${ }^{79}$ For instance, Thailand's experience of building capacity for equity monitoring and strengthening partnerships between data collection bodies and the its Ministry of Public Health fostered the development of health equity monitoring. ${ }^{80}$ While India has the benefit of rich data sources, these could be better applied to monitoring changing equity gaps and quantifying progress among disadvantaged groups. Furthermore, equity-based targets need to be fully integrated into the national, state and local level goals.

\section{Capacity building for health systems and health equity research}

There needs to be a concerted effort to improve the knowledge base of health systems research and health equity research. ${ }^{81}$ India is in the position to take a leading role in improving our knowledge of health systems research at the global level. Given that much of the implementation and decisions are made at the state and local level, there is the opportunity to actively learn from the multitude of different reforms. However, it is imperative at the outset that optimal data management systems and research design are in place, so as to capitalize on gaining knowledge from these interventions and understanding which programs and interventions work and how they impact equity in health care. This is even more important, given the iterative scaling up and rolling out these reforms, to guide where resources should be most effectively directed to improve the likelihood of success. ${ }^{79}$ Although there have been independent and internal evaluations of the NRHM, ${ }^{74-76,82}$ both of specific programs and in specific states, there is the urgent need for further independent large-scale evaluations. ${ }^{75}$

During Mexico's recent health sector reforms, their evidence-based approach to impact evaluation allowed the world to learn from their experience. ${ }^{83}$ India must adopt such an approach of rigorous impact evaluation and implementation research, ideally with a specific body commissioned with coordinating and disseminating this knowledge developed through an active sharing of best practices between and within states, as well as internationally. The National Health Systems Resource Centre is well placed to provide the necessary structure to support this, and facilitate the ongoing development of Health Management Information Systems. (see Lancet paper on HIS) Partnering with research and academic institutions to objectively assist with this process and harnessing their expertise in the methodological 
aspects of impact evaluation will create the knowledge base to more effectively pursue equity in health care. Such a commitment must be supported by more resources and increased research funding to coordinate this. ${ }^{84}$ (see Call to action) In this way, India can contribute to the limited knowledge base of operational research in health systems in developing countries and help close the 'knowledge-action' gap in health systems strengthening. ${ }^{85,86}$

\section{Deliberative process of achieving equity in healthcare}

There needs to be more meaningful consideration and development of the decision-making process relating to achieving health equity. We have only touched on some of the challenges that India's health system faces from the equity perspective, yet the central issue concerns not only what needs to be done, but how to go about achieving this. The challenge of how to prioritize and implement pro-equity health policies when resources are limited requires a deliberative process. This requires taking into consideration the implications and risks of those decisions, with monitoring of how such decisions will affect health equity. For example, epidemiologic polarization and the emerging burden of chronic disease require making choices for the allocation of resources between subpopulations with different disease patterns. Further, with India's ageing population requires deliberation of intergenerational equity in the allocation of limited resources between different age groups.

We suggest review and formalization of the process of resources allocation decisions and service delivery planning, which involves deciding the balance between central, state and local financing, and vertical and horizontal allocation efficiency, based on the best available evidence, and guided by equity concerns. This could involve adoption of a framework such as "Benchmarks for Fairness" which has been successfully adapted for use in several developing countries, such as Colombia, Pakistan and Thailand. ${ }^{87}$ Mexico's experience of embracing a transparent decision-making process for prioritizing coverage of specific health conditions under their social reforms, together with specific inputs from an Ethics Working Group, created a forum for reasonableness which was relevant, revisable and enforceable, and ultimately more legitimate. ${ }^{13}$ This is important in addressing the supply-side issue of the allocation of limited resources to different service inputs. Such an approach requires all stakeholders to take responsibility and together engage in the pursuit of reducing inequities in health care and health in India, as upheld by the Call to Action.

\section{Stakeholder responsibilities and accountabilities}

Multilaterals, national and local government, NGOs, the private sector, pharmaceutical industry, civil society and research and academic institutions all have responsibilities and roles to play in ensuring the success of achieving equity in health and indeed better health governance. ${ }^{88}$ This requires demanding accountability, transparency and better leadership and partnerships within the health system, together with systematic assessment and analysis of health system governance. Since health policy and implementation manifestly operates within the broader political context, defining iterative strategies for key players to maintain political priority for the equity in health agenda is necessary to champion this issue. This is particularly important because the potential beneficiaries represent a less powerful and less organized group, who are consequently less able to influence these reforms. ${ }^{89} \mathrm{We}$ specifically highlight the role of civil society, and the need to engage, empower and build capacity within civil society to demand equity in health and better quality health care at reasonable costs. Although the evidence to support this may be lacking, examples such as China's experience of public dissatisfaction with the fairness of its health system, demonstrates how civil society can effect change in health reform. ${ }^{10}$ Case studies commissioned by the CSDH also highlight the role of civil society in promoting health equity. ${ }^{90}$ 
Critically, India's ineffective regulatory mechanisms and legal instruments urgently need to be reformed with effective implementation strategies.(see Call to action) The growth of private sector and pharmaceutical industry has outpaced the capacity of the government and other stakeholders to institute the necessary and appropriate regulatory environment. Incentives, rules and strategies are needed to engage and persuade the industry to ensure that their obligations and responsibilities to population health and equity are upheld. This current deficiency could redefine the potential role of a more organized civil society in shaping the political agenda. In part this can be achieved through dissemination of knowledge and improvements in education to generate better health consciousness and address the demandside challenge of appropriate health seeking behavior, e.g., engagement of Accredited Social Health Activists as part of the NRHM to generate more awareness within communities of the available services. This should be complemented by improved awareness of the right to health and the right to health care, and the obligations of the health systems and government, institutions and other stakeholders to delivering this fairly.

\section{Investing in public health and primary care: cornerstones for equity in health}

Finally, priority should be given to investing in public health and primary care. Improving the existing fragmented approach to public health services through creation of a solid foundation in public health paralleled by strengthening of the primary care network would go a long way in ensuring a more equitable healthy India. ${ }^{91}$ Building the capability and capacity to plan and implement public health services from within the Ministry of Health and Family Welfare would allow for a more coordinated approach to effectively protect the population's health. ${ }^{91}$ Stronger engagement and partnerships, both within and outside government, are needed to improve public health infrastructure and better protect the most vulnerable from unjust exposure to adverse risks. Such investment in public health, together with strengthening of primary care services and targeted programs to reach out to those most in need is a fundamental step towards redressing the health inequities that exist in India. ${ }^{92}$ Primary care is arguably more complex and uncertain compared to the time of the Alma Ata declaration but building a responsive integrated primary care service which assures universal coverage is also a means to contain costs. ${ }^{93}$ The $11^{\text {th }}$ Five Year Plan, and the NRHM both emphasize the foundation of primary care, and further promote a holistic approach to intersectoral responses to complement this. ${ }^{94}$

\section{CONCLUSION}

There is a cogent moral, social and economic argument for investing in achieving equity in the health care of Indians. Recent rapid economic growth provides for a unique opportunity to increase financial commitments to support the public health system and health systems research. India can also draw on the knowledge capital of its booming technology sector to innovate and strengthen the development of health information systems, which has already begun (see Lancet paper on HIS). Furthermore, there is the opportunity to harness the capability of the domestic pharmaceutical industry by inducing it to take greater responsibility for delivering equity in health care. We have suggested principles to guide this vision. The next step is translating these into real and practical policies and effectively implementing them, and the Call to Action takes up this challenge. Yet, this focus on the role of the health system needs to be placed within the broader and bigger context of the social determinants of health, and tackling the root causes of social disadvantage. In this way, a health system built on a strong foundation of public health and primary care must be synergized with public policies that promote critical intersectoral approaches. Improved water and sanitation, food security, poverty reduction and changes to other structural factors, complemented by a more equitable health system, will help ensure more equitable health for more than a billion people. 


\section{Supplementary Material}

Refer to Web version on PubMed Central for supplementary material.

\section{Acknowledgments}

YB, SS, SVS received no funding support to carry out this study. SVS is supported by a National Institutes of Health Career Development Award (NHLBI K25 HL081275).

\section{REFERENCES}

1. Information DoMaH. , editor. World Health Organization. Global burden of disease. 2009.

2. Srinath Reddy K, Shah B, Varghese C, Ramadoss A. Responding to the threat of chronic diseases in India. The Lancet. 2005; 366(9498):1744-1749.

3. UNICEF. New York: Oxford University for UNICEF; 2009. The State of the World's Children 2009: Maternal and Newborn Health Oxford.

4. UNICEF. New York: United Nations Children's Fund; 2008. The State of the World's Children 2008: Child Survival.

5. World Health Organization. Geneva: World Health Organization; 2010. World health statistics.

6. Joe W, Mishra US, Navaneetham K. Socio-economic inequalities in child health: Recent evidence from India. Glob Public Health. 2009:1-16.

7. Balarajan Y, Villamor E. Nationally representative surveys show recent increases in the prevalence of overweight and obesity among women of reproductive age in Bangladesh, Nepal, and India. J Nutr. 2009; 139(11):2139-2144. [PubMed: 19776182]

8. Sen, G.; George, A.; Ã-stlin, P. Engendering international health : the challenge of equity. Cambridge, Mass.: MIT Press; 2002.

9. International Institute for Population Sciences. Mumbai, India: International Institute for Population Sciences; 2007. National Family Health Survey (NFHS-3), 2005-06 : India.

10. Tang S, Meng Q, Chen L, Bekedam H, Evans T, Whitehead M. Tackling the challenges to health equity in China. The Lancet. 2008; 372(9648):1493-1501.

11. HDR U. United States Human Development Report.

12. Rawls, J. A theory of justice. Cambridge, Mass.: Belknap Press of Harvard Univeristy Press; 1999.

13. Daniels, N. Just health : meeting health needs fairly. Cambridge; New York: Cambridge University Press; 2008.

14. Evans, T.; Whitehead, M.; Diderichsen, F.; Bhuiya, A.; Wirth, M., editors. Challenging inequities in health : from ethics to action. Oxford; New York: Oxford University Press; 2001.

15. Roberts, MJ. Getting health reform right : a guide to improving performance and equity. Oxford; New York: Oxford University Press; 2008.

16. World Health Organization. Geneva: World Health Organization; 2000. The world health report 2000: Health Systems: Improving Performance.

17. J Bhore, RA.; Banerjee, AC. Report of the Health Survey and Development Committee. Division, P., editor. Delhi: Government of India; 1946.

18. MoHFW. Delhi: Ministry of Health and Family Welfare, Government of India; 1983. National Health Policy.

19. MoHFW. Delhi: Ministry of Health and Family Welfare, Government of India; 2002. National Health Policy.

20. The National Health Bill: Ministry of Health and Family Welfare, Government of India. 2009.

21. Pritchett L. Is India a Flailing State?: Detours on the Four Lane Highway to Modernization. SSRN eLibrary. 2009

22. Gwatkin DR. Health inequalities and the health of the poor: what do we know? What can we do? Bull World Health Organ. 2000; 78(1):3-18. [PubMed: 10686729]

23. Hart, JTep. Commentary: Three decades of the inverse care law. BMJ. 2000; 320(7226):18-19. [PubMed: 10671038] 
24. Sen G, Iyer A, George A. Structural Reforms and Health Equity: A Comparison of NSS Surveys, 1986-87 and 1995-96. Economic and Political Weekly. 2002; 37(14):1342-1352.

25. Singh $\mathrm{CH}$, Ladusingh L. Correlates of inpatient healthcare seeking behavior in India. Indian J Public Health. 2009; 53(1):6-12. [PubMed: 19806821]

26. Gaudin S, Yazbeck AS. Immunization in India 1993-1999: wealth, gender, and regional inequalities revisited. Soc Sci Med. 2006; 62(3):694-706. [PubMed: 16085346]

27. Goddard M, Smith P. Equity of access to health care services: theory and evidence from the UK. Soc Sci Med. 2001; 53(9):1149-1162. [PubMed: 11556606]

28. NSSO. Morbidity and Health Care and Condition of the Aged: National Sample Survey Organisation, Ministry of Statistics and Programme Implementation, Government of India. 2006.

29. Mahal, AYA.; Peters, DH.; Ramana, GNV. HNP Discussion Paper. Washington, DC: The World Bank; 2001. The poor and health service use in India.

30. Peters, DH. Better health systems for India's poor : findings, analysis, and options. Washington, D.C: World Bank; 2002. Human Development N.

31. India Go. New Delhi: Ministry of Health and Family Welfare; 2009 September. National Health Accounts India, 2004-5.

32. WHO. National Health Accounts. 2009.

33. Peters DH, Rao KS, Fryatt R. Lumping and splitting: the health policy agenda in India. Health Policy Plan. 2003; 18(3):249-260. [PubMed: 12917266]

34. Selvaraj S, Karan A. Deepening Health Insecurity in India: Evidence from National Sample Surveys since 1980s. Economic and Political Weekly. 2009; 44(40):55-60.

35. CBHI. Health Infrastructure, National Health Profile (NHP) of India - 2008. 2008.

36. De Costa A, Al-Muniri A, Diwan VK, Eriksson B. Where are healthcare providers? Exploring relationships between context and human resources for health Madhya Pradesh province, India. Health Policy. 2009; 93(1):41-47. [PubMed: 19559495]

37. Lavy, V.; Germain, JM. World Bank. Washington, D.C: World Bank; 1994. Quality and cost in health care choice in developing countries.

38. Acharya LB, Cleland J. Maternal and child health services in rural Nepal: does access or quality matter more? Health Policy Plan. 2000; 15(2):223-229. [PubMed: 10837046]

39. Vissandjee B, Barlow R, Fraser DW. Utilization of health services among rural women in Gujarat, India. Public Health. 1997; 111(3):135-148. [PubMed: 9175456]

40. Rohde J, Viswanathan H. The rural private practitioner. Health Millions. 1994; 2(1):13-16. [PubMed: 12288589]

41. Das, J.; Hammer, JS. World Bank. Development Research Group. Public Services. Washington, D.C: World Bank, Development Research Group, Public Services; 2004. Strained mercy : the quality of medical care in Delhi.

42. Peters DH, Muraleedharan VR. Regulating India's health services: To what end? What future? Social Science \& Medicine. 2008; 66(10):2133-2144. [PubMed: 18313189]

43. Das Gupta, M.; Rani, M. World Bank. Development Research Group. Public Services. Washington, D.C: World Bank, Development Research Group, Public Services Team; 2004. India's public health system : how well does it function at the national level?.

44. Banerjee A, Duflo ADE. Health Care Delivery in rural Rajasthan: Poverty Action Lab Paper. 2003 February.(No. 4)

45. Banerjee A, Duflo E. Addressing Absence. The Journal of Economic Perspectives. 2006; 20:117132. [PubMed: 19169425]

46. Chaudhury N, Hammer J, Kremer M, Muralidharan K, Rogers FH. Missing in Action: Teacher and Health Worker Absence in Developing Countries. The Journal of Economic Perspectives. 2006; 20:91-116. [PubMed: 17162836]

47. Das J, Hammer J. Location, Location, Location: Residence, Wealth, And The Quality Of Medical Care In Delhi, India. Health Aff. 2007; 26(3):w338-w351.

48. Das J, Hammer J. Money for nothing: The dire straits of medical practice in Delhi, India. Journal of Development Economics. 2007; 83(1):1-36. 
49. Sreevidya S, Sathiyasekaran BWC. High caesarean rates in Madras (India): a population-based cross sectional study. BJOG: An International Journal of Obstetrics \& Gynaecology. 2003; 110(2): 106-111. [PubMed: 12618152]

50. Kent Ranson M, John KR. Quality of Hysterectomy Care in Rural Gujarat: The Role of Community-Based Health Insurance. Reproductive Health Matters. 2002; 10(20):70-81. [PubMed: 12557644]

51. Gupta I, Dasgupta P. Demand for curative health care in rural India: choosing between private, public and no care. Institute of Economic Growth. Discussion Paper Series. 2000; (No. 14/2000): $1-35$.

52. India Go. Eleventh Five Year Plan. Planning Commission. 2007.

53. BHAT R. Regulating the private health care sector: the case of the Indian Consumer Protection Act. Health Policy Plan. 1996; 11(3):265-279. [PubMed: 10160372]

54. Baru, RV. Private Health Sector in India - Raising Inequities. In: Gangolli, LV.; Duggal, R.; Shukla, A., editors. Review of Healthcare In India. Mumbai: Centre for Enquiry into Health and Allied Themes; 2005.

55. Yip W, Mahal A. The Health Care Systems Of China And India: Performance And Future Challenges. Health Aff. 2008; 27(4):921-932.

56. India Go. National Health Accounts India, 2001-2. New Delhi: Ministry of Health and Family Welfare; 2005 December.

57. Devadasan N, Ranson K, Van Damme W, Acharya A, Criel B. The landscape of community health insurance in India: An overview based on 10 case studies. Health Policy. 2006; 78(2-3):224-234. [PubMed: 16293339]

58. O'Donnell O. Access to health care in developing countries: breaking down demand side barriers. Cadernos de Saúde Pública. 2007; 23:2820-2834.

59. Bonu S, Bhushan I, Rani M, Anderson I. Incidence and correlates of 'catastrophic' maternal health care expenditure in India. Health Policy Plan. 2009; 24(6):445-456. [PubMed: 19687135]

60. Ajay Mahal, AK.; Engelgau, Michael. Health, Nutrition and Population (HNP) Discussion Paper. Washington, DC, USA: World Bank; 2010. The Economic Implications of Non-Communicable Disease for India.

61. Garg CC, Karan AK. Reducing out-of-pocket expenditures to reduce poverty: a disaggregated analysis at rural-urban and state level in India. Health Policy Plan. 2009; 24(2):116-128. [PubMed: 19095685]

62. van Doorslaer E, O'Donnell O, Rannan-Eliya RP, et al. Effect of payments for health care on poverty estimates in 11 countries in Asia: an analysis of household survey data. The Lancet. 2006; 368(9544):1357-1364.

63. Krishna A. Escaping poverty and becoming poor: Who gains, who loses, and why? World Development. 2004; 32(1):121-136.

64. NSSO. National Sample Survey Organisation (NSSO). 2009.

65. Health CoMa. Financing of Health in India. In: Rao, S., editor. Background Papers - Financing and Delivery of Health Care Services in India. New Delhi: Ministry of Health \& Family Welfare, Government of India; 2005 August.

66. Selvaraj, SaVN. Access to Medicines in India:Issues, Challenges and Response. In: India Health Report - 2010. , editor. Business Standard Pub.; 2010.

67. Sengupta A, Joseph Reji K, Modi Shilpa, Syam Nirmalya. Studies SfEaS, with aCfTaDic, Organization. tWH. 'Economic Constraints to Access to Essential Medicines in India'. 2008

68. Ensor T, Cooper S. Overcoming barriers to health service access: influencing the demand side. Health Policy Plan. 2004; 19(2):69-79. [PubMed: 14982885]

69. Lewis M. Governance and Corruption in Public Health Care Systems: Center for Global Development. 2006

70. Thampi, GK. Corruption in South Asia: Insights and Benchmarks from Citizen Feedback Surveys in Five Countries. In: International T. , editor. 2002. 
71. Cleland JG, van Ginneken JK. Maternal education and child survival in developing countries: The search for pathways of influence. Social Science \& Medicine. 1988; 27(12):1357-1368. [PubMed: 3070762]

72. Griffiths P, Stephenson R. Understanding Users: Perspectives of barriers to maternal health care use in Maharashtra, India. Journal of Biosocial Science. 2001; 33(03):339-359. [PubMed: 11446398]

73. Nutbeam D. Health literacy as a public health goal: a challenge for contemporary health education and communication strategies into the 21 st century. Health Promot. Int. 2000; 15(3):259-267.

74. National Rural Health Mission, Meeting People's Health Needs In Partnerships With States. Thr Journey So Far, 2005-2010: Ministry of Health and Family Welfare, Government of India.

75. Gill K. A Primary Evaluation of Service Delivery under the National Rural Health Mission (NRHM): Findings from a Study in Andhra Pradesh, Uttar Pradesh, Bihar and Rajasthan Working Paper 1/2009 - PEO: Planning Commission of India. 2009 May.

76. Nirupam Bajpai JDS, Ravindra H. Dholakia Improving access, service delivery and efficiency of the public health system in rural India Mid-term evaluation of the National Rural Health Mission The Earth Institute at Columbia University. 2009 October.

77. Commission on Social Determinants of Health. Geneva: World Health Organization; 2008. Closing the gap in a generation : health equity through action on the social determinants of health : final report of the commission on social determinants of health.

78. Gwatkin DR, Bhuiya A, Victora CG. Making health systems more equitable. Lancet. 2004; 364(9441):1273-1280. [PubMed: 15464189]

79. Chan M, Kazatchkine M, Lob-Levyt J, et al. Meeting the demand for results and accountability: a call for action on health data from eight global health agencies. PLoS Med. 7(1) e1000223.

80. Tangcharoensathien V, Limwattananon S, Prakongsai P. Improving Health-Related Information Systems to Monitor Equity in Health: Lessons from Thailand. The Economics of Health Equity, Forthcoming. 1905

81. Frenk J, Horton R. Evidence for health-system reform: a call to action. The Lancet. 2006; 368(9529):3-4.

82. Lim SS, Dandona L, Hoisington JA, James SL, Hogan MC, Gakidou E. India's Janani Suraksha Yojana, a conditional cash transfer programme to increase births in health facilities: an impact evaluation. The Lancet. 375(9730):2009-2023.

83. Frenk J, Sepúlveda J, Gómez-Dantés O, Knaul F. Evidence-based health policy: three generations of reform in Mexico. The Lancet. 2003; 362(9396):1667-1671.

84. Fryatt R, Mills A, Nordstrom A. Financing of health systems to achieve the health Millennium Development Goals in low-income countries. Lancet. 375(9712):419-426. [PubMed: 20113826]

85. Frenk J. The Global Health System: Strengthening National Health Systems as the Next Step for Global Progress. PLoS Med. 7(1) e1000089.

86. Reich MR, Takemi K, Roberts MJ, Hsiao WC. Global action on health systems: a proposal for the Toyako G8 summit. Lancet. 2008; 371(9615):865-869. [PubMed: 18328932]

87. Daniels, N.; Light, D.; Caplan, RL. Benchmarks of fairness for health care reform. New York: Oxford University Press; 1996.

88. Siddiqi S, Masud TI, Nishtar S, et al. Framework for assessing governance of the health system in developing countries: Gateway to good governance. Health Policy. 2009; 90(1):13-25. [PubMed: 18838188]

89. Olson, M. The logic of collective action : public goods and the theory of groups. Cambridge, Mass: Harvard University Press; 1971.

90. Health WCoSDo. CHALLENGING INEQUITY THROUGH HEALTH SYSTEMS: Final Report. In: Lucy Gilson, JD.; Rene, Loewenson; Victoria, Francis, editors. Knowledge Network on Health Systems. Geneva: World Health Organization; 2007.

91. Das Gupta, M.; Shukla, R.; Somanathan, TV.; Datta, KK. How might India's public health systems be strengthened ?. The World Bank. 2009.

92. World Health Organization. Geneva: World Health Organization; 2008. The world health report 2008 : primary health care now more than ever : introduction and overview. 
93. Lawn JE, Rohde J, Rifkin S, Were M, Paul VK, Chopra M. Alma-Ata 30 years on: revolutionary, relevant, and time to revitalise. Lancet. 2008; 372(9642):917-927. [PubMed: 18790315]

94. NRHM. National Rural Health Mission.

95. India Registrar G, Census C. New Delhi: Office of the Registrar General \& Census Commissioner, India, Ministry of Home Affairs; 2008. Census atlas of India, 2001.

96. Kawachi I, Subramanian SV, Almeida-Filho N. A glossary for health inequalities. Journal of Epidemiology and Community Health. 2002; 56(9):647-652. [PubMed: 12177079]

97. Harper S, King NB, Meersman SC, Reichman ME, Breen N, Lynch J. Implicit value judgments in the measurement of health inequalities. Milbank Q. 88(1):4-29. [PubMed: 20377756]

98. Whitehead, M. Concepts and principles of equity in health. Copenhagen: WHO Regional Office for Europe; 1990. 


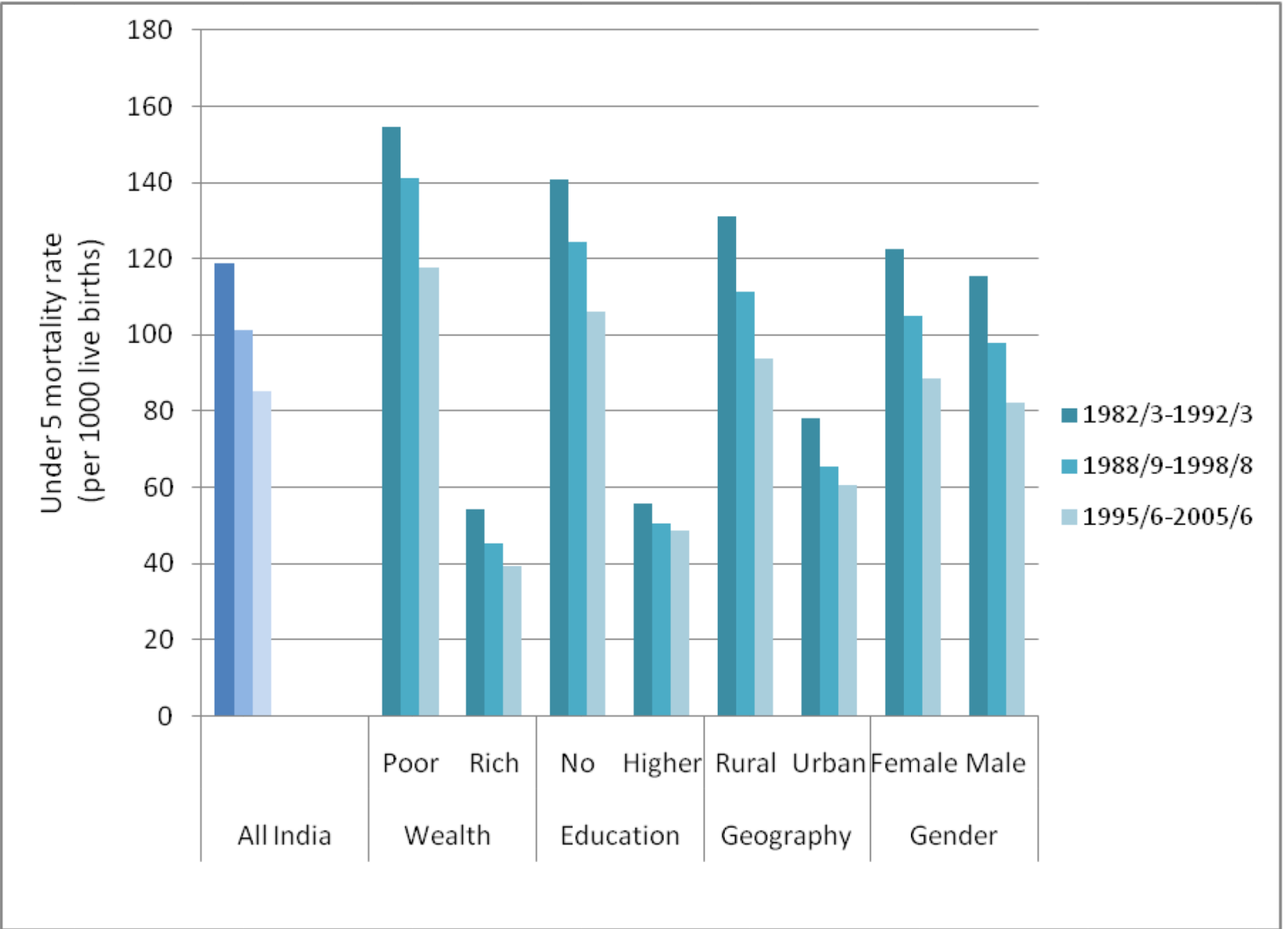

Source: NFHS 1992/3, NFHS 1998/9 and NFHS 2005/6

Notes: Under-5 mortality rates for the ten-year period preceding the survey, by selected background characteristics (excludes month of interview from analysis); Inequalities are presented in the following manner: Wealth: poorest quintile vs. richest quintile; Education: no education vs. higher education.

Figure 1.

Inequalities in Under-5 Mortality along different dimensions in India 


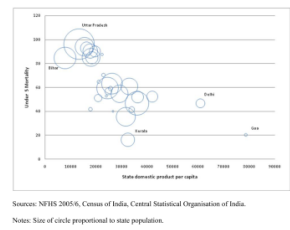

Figure 2.

Association between Under-5 Mortality and State domestic product per capita (at factor cost at current prices) 


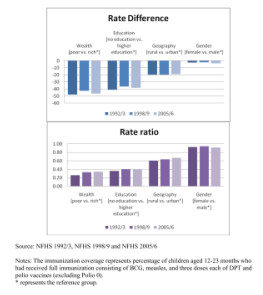

Figure 3.

Trends in inequalities in immunization coverage along different dimensions expressed in rate difference (absolute inequalities) and rate ratio (relative inequalities) 


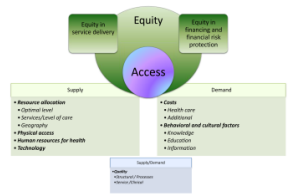

Figure 4.

Conceptual model for understanding challenges to equity in health care 


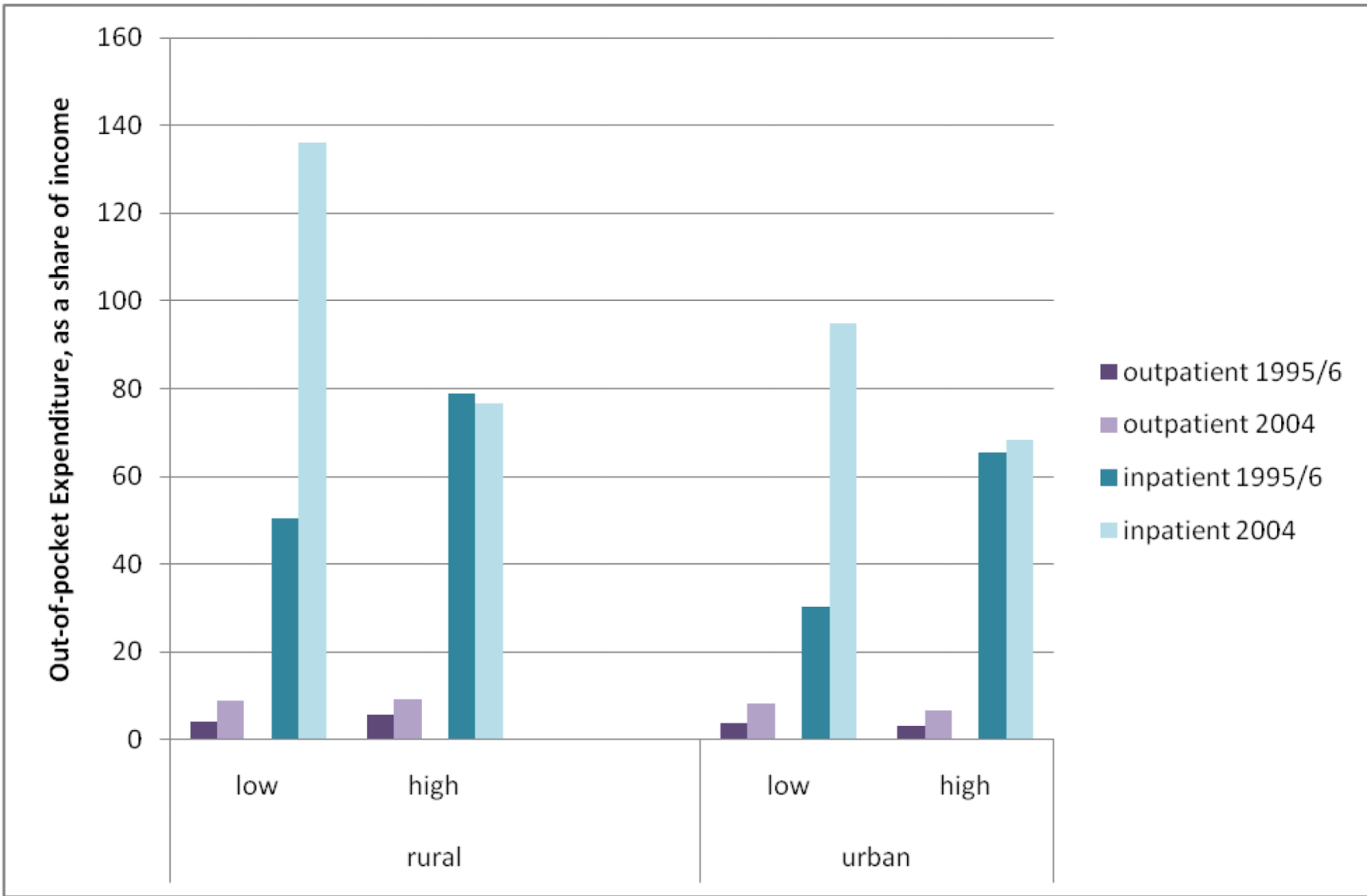

Source: NSSO $52^{\text {nd }}, 60^{\text {th }}$ rounds, adapted from Yip W, Mahal A. The Health Care Systems Of China And India: Performance And Future Challenges. Health Aff. 2008 July 1, 2008; 27(4):921-32)

Notes: Annual income per capita (accounts for household size and standardized to 1993 Rupees). 'Low' indicates the lowest quintile, and 'high' the highest quintile income group. Outpatient episode is per outpatient visit, and inpatient episode is per hospital admission.

Figure 5.

Trends in out-of-pocket health expenditures in households per episode, as a share of income by income group and residence 


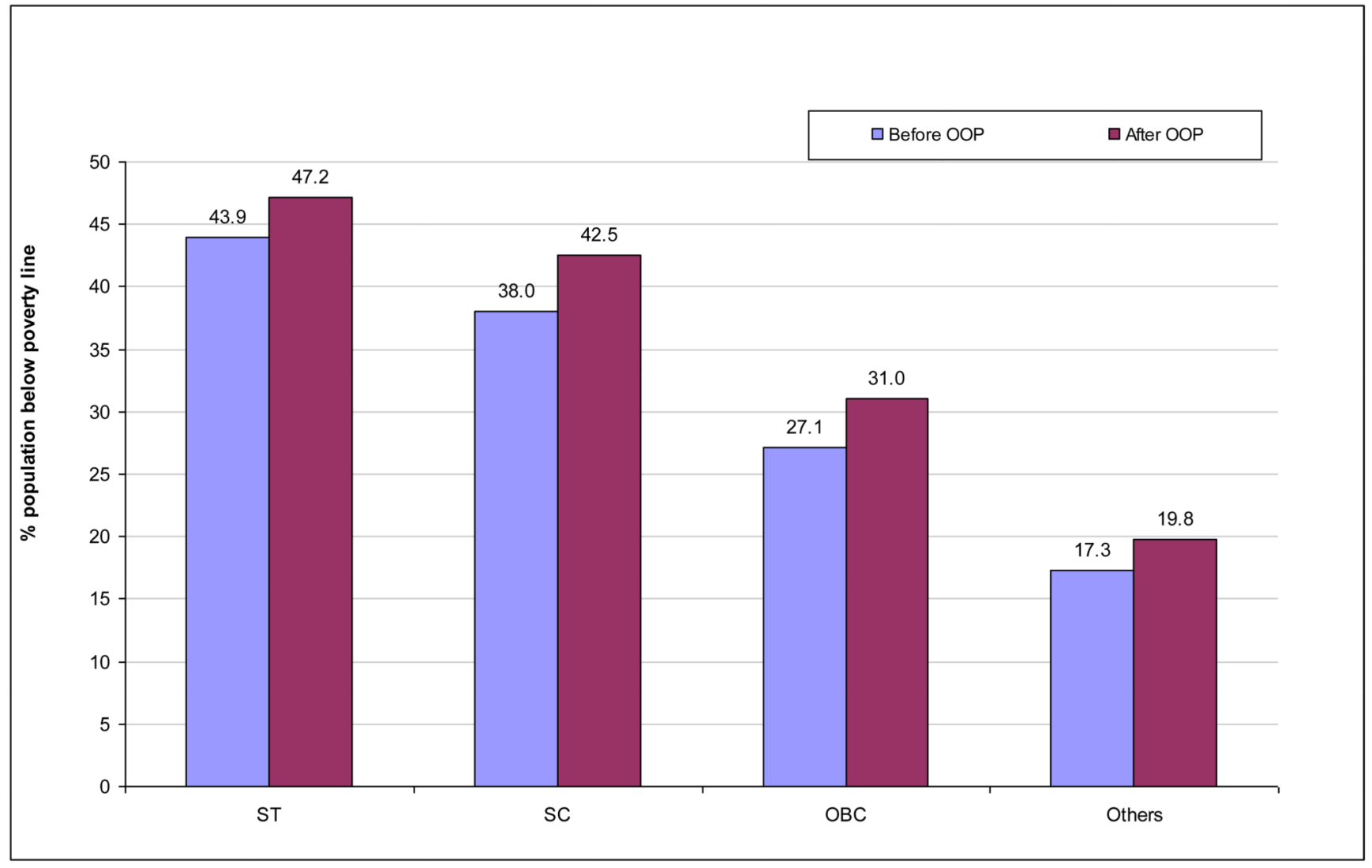

Source: Authors' calculations based on Consumer Expenditure Surveys 1993-94 (50 ${ }^{\text {th }}$ Round), $1999-2000$ (55 ${ }^{\text {th }}$ Round) and 2004-5 (61st Round), NSSO

Notes: In India, official poverty lines are based on a calorie norm of 2,400 calories per capita per day for rural areas and 2,100 calories per capita per day for urban areas. The proportion of population with monthly per capita expenditure (MPCE) less than the specified poverty line (calorie norm) are considered below poverty. Before and after OOP refers to a situation where before OOP is percent population below poverty without taking into consideration OOP, while the latter denotes percent population below poverty after taking into account OOP.

Figure 6.

Impact of out-of-pocket payments (OOP) on poverty ratios in India 